\title{
Utilization of a multimodal preoperative pain regimen prior to gynecologic oncology exploratory laparotomies
}

\author{
Lauren C. Hand, MD \\ Thomas Jefferson University
}

Alison Vogell, MD

Lahey Hospital and Medical Center

Talia Maas, MD

Thomas Jefferson University

Kristina Masi, MD

Thomas Jefferson University Hospital

Rebecca J. Mercier MD MPH

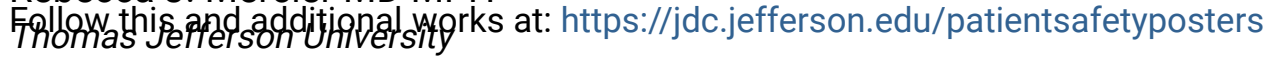

Part of the Medicine and Health Sciences Commons

beet us knownthow access to this document benefits you

\section{Recommended Citation}

Hand, MD, Lauren C.; Vogell, MD, Alison; Maas, MD, Talia; Masi, MD, Kristina; Mercier MD MPH, Rebecca J.; Rosenblum, MD, PhD, Norman G.; and Kim, MD, Christine H., "Utilization of a multimodal preoperative pain regimen prior to gynecologic oncology exploratory laparotomies" (2017). House Staff Quality Improvement and Patient Safety Conference (2016-2019). Poster 53.

https://jdc.jefferson.edu/patientsafetyposters/53

This Article is brought to you for free and open access by the Jefferson Digital Commons. The Jefferson Digital Commons is a service of Thomas Jefferson University's Center for Teaching and Learning (CTL). The Commons is a showcase for Jefferson books and journals, peer-reviewed scholarly publications, unique historical collections from the University archives, and teaching tools. The Jefferson Digital Commons allows researchers and interested readers anywhere in the world to learn about and keep up to date with Jefferson scholarship. This article has been accepted for inclusion in House Staff Quality Improvement and Patient Safety Conference (2016-2019) by an authorized administrator of the Jefferson Digital Commons. For more information, please contact: JeffersonDigitalCommons@jefferson.edu. 


\section{Authors}

Lauren C. Hand, MD; Alison Vogell, MD; Talia Maas, MD; Kristina Masi, MD; Rebecca J. Mercier MD MPH; Norman G. Rosenblum, MD, PhD; and Christine H. Kim, MD 
Utilization of a multimodal preoperative pain regimen prior to gynecologic oncology exploratory laparotomies.

Jefferson。

Lauren C Hand MD1, Alison Vogell MD², Talia Maas MD ${ }^{1}$, Kristina Masi MD 1, Rebecca Mercier MD 1, Norman G. Rosenblum MD, PhD³,

Christine H. Kim MD³

1. Department of Obstetrics and Gynecology, Thomas Jefferson University Hospital

2. Division of General Gynecology, Lahey Hospital \& Medical Center

3. Division of Gynecologic Oncology, Department of Obstetrics and Gynecology, Thomas Jefferson University Hospital

\section{Background}

Postoperative analgesia is an important component of patient care and surgical outcomes. It is thought that inadequate pain control leads to decreased ambulation, increased morbidity, increased use of opioids, and increased length of hospital stay. A multimodal approach to pain control has been shown in other surgical fields to reduce the use of post-operative opioid use.

\section{Objective}

The aim of this study was to evaluate the use of a combination of non-opioid preoperative pain medications including Tylenol, Lyrica, and Celecoxib (TLC) in patients undergoing gynecologic oncologic exploratory laparotomies. We evaluated postoperative narcotic use in morphine equivalents (ME), as well as pain scores, anti-emetic use, and length of stay.

Methods

A retrospective cohort study was performed of all gynecologic oncologic patients who underwent exploratory laparotomies from February 2011 to April 2013 by one surgeon at a tertiary care center who either received TLC or did not. The primary outcome was post-operative narcotic use in $\mathrm{ME}$ during the first 24 hours after surgery. Secondary outcomes included postoperative pain scores, total ME during the hospital stay, and length of stay. For the purpose of standardizing, all narcotics were converted to either PO or IV ME. Data was analyzed using STATA Version 12 with a combination of Kruskal-Wallis test, t-test, and chi square.

\section{Results}

- 84 patients received TLC and 64 patients did not receive TLC

- Demographics were similar between the two groups including age, race, BMI, comorbidities, smoking, number of prior laparotomies, and type of cancer

Table 1: Non-opioid postoperative pain control

\begin{tabular}{|c|c|c|c|}
\hline Variable & $\begin{array}{c}\text { TLC } \\
(\mathbf{n = 8 4 )}\end{array}$ & $\begin{array}{c}\text { NO TLC } \\
(\mathbf{n = 6 4 )}\end{array}$ & $\mathbf{P}$ \\
\hline & $\mathbf{n ~ ( \% )}$ & $\mathbf{n}(\mathbf{\% )}$ & \\
\hline Postop IV Tylenol & & & $<\mathbf{0 . 0 1}$ \\
\hline Yes & $80(96)$ & $3(4)$ & \\
\hline Postop IV Motrin & & & 0.07 \\
\hline Yes & $4(100)$ & $0(0)$ & \\
\hline Postop PO Lyrica & & & $\mathbf{0}$ \\
\hline Yes & $49(96)$ & $2(4)$ & \\
\hline Postop IV Toradol & & & $\mathbf{0}$ \\
\hline Yes & $1(2)$ & $43(97)$ & \\
\hline
\end{tabular}

Table 2: Analysis of Morphine Equivalents and Pain Scores

\begin{tabular}{|l|c|c|c|}
\hline & $\begin{array}{r}\text { TLC } \\
\text { Median }\end{array}$ & $\begin{array}{c}\text { No TLC } \\
\text { Median }\end{array}$ & P \\
\hline Total MEQ P0 + IV 0-72h & 90.6 & 123.8 & $<\mathbf{0 . 0 1}$ \\
\hline Total MEQ IV 0-72h & 71.7 & 106.8 & $<\mathbf{0 . 0 1}$ \\
\hline Total MEQ P0 0-72h & 16 & 16 & 0.58 \\
\hline Total MEQ P0+IV 0-24h & 40.2 & 66 & $<\mathbf{0 . 0 1}$ \\
\hline Total MEQ IV 0-24h & 39.5 & 66 & $<\mathbf{0 . 0 1}$ \\
\hline Total MEQ P0 0-24h & 0 & 0 & 0.21 \\
\hline Total MEQ P0+IV 24-48h & 26.1 & 28.1 & 0.94 \\
\hline Total MEQ IV 24-48h & 22.8 & 26.8 & 0.94 \\
\hline Total MEQ P0 24-48h & 0 & 0 & 0.30 \\
\hline Total MEQ P0+IV 48-72h & 14.7 & 16 & 0.36 \\
\hline Total MEQ IV 48-72h & 4.0 & 4.0 & 0.78 \\
\hline Total MEQ P0 48-72h & 0 & 0 & 0.55 \\
\hline Mean pain 0-24h & 4.7 & 3.5 & $\mathbf{0 . 0 1}$ \\
\hline Mean pain 24-48h & 3.5 & 3.7 & 0.76 \\
\hline Mean pain 48-72h & 3.3 & 3.8 & 0.30 \\
\hline Mean max pain 0-24h & 6 & 7 & $<\mathbf{0 . 0 1}$ \\
\hline Mean max pain 24-48h & 5 & 5 & 0.32 \\
\hline Mean max pain 48-72h & 5 & 5 & 0.90 \\
\hline Mean min pain 0-24h & 0 & 2 & $<\mathbf{0 . 0 1}$ \\
\hline Mean min pain 24-48h & 2 & 2 & 0.73 \\
\hline Mean min pain 48-72h & 2 & 2 & 0.14 \\
\hline
\end{tabular}

Table 3: Adjusted Means ANOVA Analysis

\begin{tabular}{|l|c|c|c|}
\hline Outcome of Interest & \multicolumn{2}{|c|}{ Adjusted Means } & P \\
& Mean (95\% CI of adjusted mean) & \\
\hline Total MEQ all 0-72h & $122.6(58.6,186.6)$ & $214.3(133.5,295.1))$ & $\mathbf{0 . 0 5}$ \\
\hline Total MEQ iv 0-72h & $94.7(40.1-149.4)$ & $169.4(100.4,238.5)$ & $\mathbf{0 . 0 1}$ \\
\hline MEQ all 0-24h & $64.6(15.0,114.3)$ & $111.9(49.2,174.6)$ & $\mathbf{0 . 0 4}$ \\
\hline MEQ iv 0-24h & $64.3(14.7,113.9)$ & $111.9(49.2,174.6)$ & $\mathbf{0 . 0 4}$ \\
\hline Mean pain 0-24h & $3.4(2.6,4.3)$ & $4.5(3.4,5.6)$ & $\mathbf{0 . 0 1}$ \\
\hline Mean min pain 0-24h & $1.4(0.61,2.2)$ & $1.9(0.91,2.9)$ & $\mathbf{0 . 0 3}$ \\
\hline Mean max pain 0-24h & $5.6(4.6,6.6)$ & $7.2(5.9,8.5)$ & $\mathbf{0 . 0 2}$ \\
\hline
\end{tabular}

Significance and/or lessons learned:

Using a multi-modal approach to pain control pre-operatively can help reduce patient's IV narcotic usage in the first 24 hours after surgery. The mean pain score in the 24 hours after surgery was significantly less in the group that received TLC. Additionally, both the maximum and minimum pain scores in the first 24 hours after surgery were also significantly less in the group that received TLC. The total combined PO and IV MEs, as well as the total IV ME were also reduced over the entire postoperative period in the group that received TLC. Using ANOVA analysis, statistical significance was retained, though minimal pain scores had a weak association.

\section{Future Directions}

-Enact TLC pre-operative regimen in routine gynecologic cases

-Evaluate the use of TLC in minimally invasive techniques

-Evaluate the use on on-q pain systems compared to exparel intraoperative 